\title{
Walnut oil deacidification by liquid-liquid extraction with ethanol in a single- and multistage crossflow process $^{\text {th }}$
}

\author{
Roua Bou Orm ${ }^{1}$, Morgane Citeau ${ }^{2}$, Audrey Comitis ${ }^{2}$, Raphaëlle Savoire ${ }^{3}$, Christelle Harscoat-Schiavo ${ }^{3}$, \\ Pascale Subra-Paternault ${ }^{3}$, Patrick Carré ${ }^{, *}$, Jean David Leao ${ }^{4}$ and Florent Joffre ${ }^{4}$ \\ ${ }^{1}$ GEPEA ONIRIS UMR 6144 CNRS, rue de Géraudière-CS 8225, 44332 Nantes, France \\ 2 OLEAD, 11, rue Gaspard Monge, 33610 Canéjan, France \\ ${ }^{3}$ Univ. Bordeaux, CNRS, Bordeaux INP, CBMN UMR 5248, Bat 14, Allée Geoffroy Saint Hilaire, 33600 Pessac, France \\ ${ }^{4}$ ITERG, 11, rue Gaspard Monge, 33610 Canéjan, France
}

Received 7 February 2020 - Accepted 9 June 2020

\begin{abstract}
Liquid-liquid extraction of vegetable oil with ethanol predominantly removes the components having the greatest affinity for ethanol, such as free fatty acids responsible for the acidity of oil, but also some contaminants such as phthalates. The aim of this work is to study the effect of several operating parameters on the deacidification process: the initial free fatty acid content in oil (3.1, 5.8, 7.6 and $11.7 \%$ OA eq.), the ethanol-water content in solvent $(70.0 / 30.0,80.0 / 20.0,87.8 / 12.2$ and $95.6 / 4.4 \mathrm{~g} / \mathrm{g})$, and the oil/solvent ratio $(0.50,0.75$ and $1.00 \mathrm{~g} / \mathrm{g})$. The economic assessment of the deacidification based on the costs of distilling solvent and neutral oil loss showed that the use of solvents containing 82 to $90 \mathrm{wt} . \%$ of ethanol enables to achieve a trade-off between efficiency of the extraction of free fatty acid and the neutral oil losses. A threestage crosscurrent extraction using a solvent at $88.6 \mathrm{wt} . \%$ of ethanol (global solvent/oil ratio: $8.0 \mathrm{~g} / \mathrm{g}$ ) reduced the free fatty acid content from $5.8 \% \mathrm{OA}$ eq. (in crude walnut oil) to $0.3-0.4 \% \mathrm{OA}$ eq. with a loss of $4.0 \%$ of neutral oil mass. Regarding the extraction of phthalates, our results showed that the lower the water content in the hydroethanolic solvent, the more efficient the extraction of butyl benzyl phthalate(BBP). Moreover, extraction with ethanol has successfully reduced the BBP content below the current regulatory limit.
\end{abstract}

Keywords: vegetable oil / ethanol / free fatty acids / response surface analysis / phthalates

Résumé - Désacidification de l'huile de noix par extraction liquide-liquide à l'éthanol dans un procédé à courants croisés à un ou plusieurs étages. L'extraction liquide-liquide de l'huile végétale par de l'éthanol permet d'éliminer prioritairement les composants ayant le plus d'affinité avec l'éthanol tels que les acides gras libres responsables de l'acidité de l'huile, mais aussi certains contaminants tels que les phtalates. Ce travail vise à analyser l'influence de différents paramètres opératoires du procédé de désacidification à l'éthanol : la teneur initiale en acides gras libres de l'huile ( 3,$1 ; 5,8 ; 7,6$ et $11,7 \%$ eq. AO), la teneur en éthanoleau du solvant $(70,0 / 30,0 ; 80,0 / 20,0 ; 87,8 / 12,2$ et $95,6 / 4,4 \mathrm{~g} / \mathrm{g})$ et le ratio huile/solvant $(0,50,0,75$ et $1,00 \mathrm{~g} / \mathrm{g})$. L'évaluation économique basée sur les coûts de distillation du solvant et des pertes en huile neutre, montrent que l'utilisation d'un solvant contenant 82-89\% d'éthanol permettrait d'obtenir un bon compromis entre efficacité d'extraction des acides gras libres et pertes en huile neutre. Un procédé d'extraction en courant croisé de 3 étages utilisant de l'éthanol à $88,6 \%$ (ratio solvant/huile total : $8,0 \mathrm{~g} / \mathrm{g}$ ) a permis de réduire l'acidité de l'huile de noix de $5,8 \%$ eq. $\mathrm{AO}$ (dans l'huile brute) à $0,3-0,4 \%$ eq. AO avec une perte d'huile neutre totale de $4,0 \%$. D'un point de vue de l'extraction des phtalates, nos résultats montrent que plus le solvant éthanolique est pauvre en eau, mieux il extrait le butyl benzyl phtalate (BBP). De plus, l'extraction à l'éthanol a permis de réduire la teneur en BBP en dessous du seuil réglementaire actuel.

Mots clés : huile végétale / éthanol / acides gras libres / méthode des surfaces de réponses / phtalates

\footnotetext{
it Contribution to the Topical Issue "Technological challenges in oilseed crushing and refining / Défis technologiques de la trituration et du raffinage des oléagineux".

*Correspondence: p.carre@iterg. com
} 


\section{Introduction}

Walnut oil is gaining interest as a dressing oil because of its rich nutty flavour and its health benefits (Amaral et al., 2003; Poggetti et al., 2018; Gao et al., 2019). Most of the walnut oil sold in French supermarkets is a mixture of virgin oil and refined oil. Virgin oil is produced from good quality fruits by traditional mechanical extraction, involving shelling, kernel toasting (or not, to intensify the taste), pressing and filtering. Refined oil is produced from low grade fruits or fruits fragments yielding crude oil with high oleic acidity and endemic contamination by phthalates, for example.

The main drawback of walnut oil is its high sensitivity to oxidation, especially because of its high unsaturated fatty acid content. Free fatty acids (FFA) act as pro-oxidants in the oil (Miyashita and Takagi, 1986; Mistry and Min, 1987; Frega et al., 1999). The acidity range of crude walnut oil is around $0.5-10.0 \%$ (Prasad, 2003), while the accepted level of free fatty acid content in edible oil is $0.3 \%$ or less (Codex Alimentarius, 2009). The high level of free fatty acids may come from enzyme hydrolysis caused by endogenous enzymes released when the nut is damaged (Ortiz et al., 2019), and by exogenous enzymes from yeasts and molds in presence of moisture at favourable temperatures. The FFA level will therefore depend on the care taken in the harvesting, storage, and crushing conditions.

Oil deacidification is industrially performed by chemical (FFA $<2 \%$ ) or physical (FFA $>2 \%$ ) methods depending on its initial acid content. The physical method is recommended for the deacidification of highly acidic oils as it results in less neutral oil loss than the chemical method. However, the following problems are associated with the conventional methods: high oil loss, excessive water consumption and production of waste by chemical neutralisation or a risk of degradation of the oil quality following heat treatments (Bhosle and Subramanian, 2005; Rodrigues et al., 2014). As a result, it is still imperative to find an economical and less damaging method of eliminating free fatty acids.

Currently, the deacidification of oils by solvent extraction (particularly by ethanol) represents a promising alternative technique to removing free fatty acids. It is a "liquid-liquid extraction" based on the difference of solubility of FFA (and other polar lipids) and triacylglycerol (TAG) in solvent. Alcohols, often used as a solvent, contain a hydroxyl group capable of hydrogen bonding with the hydrogen of the FFA carboxyl group. This bond would explain the greater solubility of FFA in ethanol compared to TAG. This method has been tested on various vegetable oils such as rice bran oil (Rodrigues et al., 2014), corn oil (Pina and Meirelles, 2000), groundnut oil (Shah and Venkatesan, 1989) or model oils based on brazil nut and macadamia nut oils (Rodrigues et al., 2005), sunflower oils (Cuevas et al., 2009) or canola oil (Batista et al., 1999). This process has been drawing attention because of its advantages in comparison to physical and chemical refining. By reducing the acidity, this step establishes milder conditions during subsequent refinement, and generates fewer undesirable compounds as an added benefit.

In our study, ethanol has been chosen as a solvent because of its advantages, particularly its high affinity for free fatty acids at ambient temperature, its low toxicity and its easy removal under mild conditions (Batista et al., 1999; Bhosle and
Subramanian, 2005). It is a solvent allowed by the European Commission regulation for organic food production (ECR No. 889/2008) and has a good consumer acceptability as well. Experimental deacidification studies by liquid-liquid extraction have emphasised the strong effect of the water content in ethanol, the initial fatty acid content of oil, and the vegetable oil type on the fatty acid distribution between demixed oil and the solvent-rich phase (Rodrigues et al., 2005; Cuevas et al., 2009; Chiyoda et al., 2010; Shiozawa et al., 2015). The water content in ethanol seems to have the most important impact on the solubility of the components and on their distribution between oil and alcoholic phases. By increasing the solvent polarity, the addition of water to an ethanolic solvent has been shown to reduce the solubility of the neutral oil in the solvent while maintaining a sufficiently high level of extraction of FFA, thereby leading to a significant increase in the solvent selectivity between FFA and neutral oil (Rodrigues et al., 2003, 2005, 2007). Temperature was found to increase the miscibility of lipids in ethanol, but it affects more significantly the distribution of FFA in the solvent-rich phase when ethanol with high water content is used (Cuevas et al., 2009). According to Gonçalves et al. (2016), the increase in the amount of solvent relative to the mass of oil increases the FFA extraction yield and the neutral oil losses, but its effect on neutral oil losses decreases with the increase of the water content in ethanol. Multiple extraction stages were investigated by Rodrigues et al. (2014) while carrying out a deacidification of rice bran oil by continuous liquid-liquid extraction using ethanol at 94.2 wt.\% alcohol in crossflow. Results showed a complete deacidification of oil containing initially $8.5 \%$ FFA by implementing five extraction stages $\left(25^{\circ} \mathrm{C}\right.$, ratio $\mathrm{S} / \mathrm{O}$ : $1.2 \mathrm{ml} / \mathrm{ml} / \mathrm{stage}$ ), resulting in only $4.0 \%$ neutral oil losses.

Along the supply chain, vegetable oils can be contaminated by various components, including phthalates (Lacoste, 2014). A 2009 study reported a concentration of $43 \mathrm{ppm}$ of di-2(ethylhexyl) phthalate (DEHP) in a walnut oil sample (Lacoste, 2014). Phthalates are dialkyl or alkyl aryl esters of phthalic acid commonly used as additives to increase the flexibility of plastic materials. Butyl benzyl phthalate (BBP) for example is commonly added in polyvinyl chloride (PVC), polyurethane (PU), polysulfide or acrylic-based polymers that are found in the construction of food conveyor belts, food wrapping materials, vinyl tiles, adhesives... (LCSP, 2011). As is the case with many phthalates, BBP is known for it possible adverse environmental and human health effects, in particular its endocrine disrupting effect (ECHA, 2014). Despite the European Commission Regulation (ECR No. 10/2011) that prohibited the use of some phthalates (DBP (Dibutyl phthalate), BBP, DEHP, DINP (Diisononyl phthalate) and DIDP (Diisodecyl phthalate)) in plastic materials coming in contact with fatty foods, recent studies showed that edible vegetable oils still contain traces of phthalates (Nanni et al., 2011; Bi et al., 2013). Currently, phthalates could mainly come from equipment (plastic bags containing initial seeds or fruits, conveyor belts, tubes, piping systems, tanks) used in oil production processes (Lacoste et al., 2010; Nanni et al., 2011; Bi et al., 2013). Nanni et al. (2011) showed that solvent extraction and refining reduced the final phthalate content in oil. Pages et al. (2010) demonstrated that the deodorisation step of the conventional refining process carried out at high temperature and under vacuum and with steam stripping 
Table 1. Levels of factors.

\begin{tabular}{lccc}
\hline Coded variable & $(-1)$ & 0 & $(+1)$ \\
\hline Initial FFA content in oil (\% OA eq.) & 3.1 & 7.6 & 11.7 \\
Oil/solvent ratio (g/g) (solvent/oil ratio $(\mathrm{g} / \mathrm{g}))$ & $0.50(2.00)$ & $0.75(1.33)$ & $1.00(1.00)$ \\
Ethanol content in solvent (wt.\%) & 80.0 & 87.8 & 95.6 \\
\hline
\end{tabular}

$\left(220-240{ }^{\circ} \mathrm{C}, 4 \mathrm{~h}\right)$ reduced the phthalate content by $63-94 \%$ depending on the molecular weight of the phthalate. Because phthalates are soluble in ethanol, a second topic in our article examined the possible simultaneous removal of free fatty acids and phthalates by extraction with ethanol.

The present work reports on the implementation of a deacidification process for walnut oil. The objective was to study the effect of several parameters on the deacidification efficiency: initial free fatty acid content of the oil, ethanolwater composition of the extracting solvent, and oil/solvent ratio. Because the literature has revealed complex relationships between effects of parameters on deacidification, a first set of experiments was designed to produce data that was analysed via response surface methodology to establish the role of the influencing parameters and their interactions. The second set of experiments tested a multistage crossflow extraction to remove FFA and study the effect of ethanol (ethanol-water composition of solvent and solvent amount) on the extraction of BBP.

\section{Materials and methods}

\subsection{Design of experiments}

Material: Hydroethanolic solvents with different ethanol contents $(80.0,87.8$ and 95.6 wt.\%) were prepared by the addition of demineralised water to anhydrous ethanol with a purity $>99.5 \%$ (Quaron, France). Crude walnut oil from mechanical pressing and refined walnut oil having a free fatty acid content of respectively 5.8 and $0.4 \%$ (expressed as oleic acid equivalent (AO eq.)) were purchased from the industrial and consumer market.

To increase the free fatty acid content of walnut oil, the crude oil was partially hydrolysed according to an internal method based on the saponification by potassium hydroxide and the subsequent neutralisation by acid. More specifically, partial hydrolysis was performed by first adding a known volume of an aqueous solution of potassium hydroxide at $3.2 \mathrm{M}$ to the oil, in the ratio of $2.679 \mathrm{~L}$ per $\mathrm{kg}$ of oil. A reaction with triacylglycerols (TAG), diacylglycerols (DAG) and monoacylglycerols (MAG) takes place, with the production of DAG, MAG, FFA and glycerol. After $30 \mathrm{~min}$ of stirring at $25^{\circ} \mathrm{C}$, an aqueous solution of chlorhydric acid at $38 \mathrm{wt} . \%$ was added stoichiometrically to stop the hydrolysis by neutralising potassium hydroxide. After stirring, cyclohexane was added to recover the oil by liquid-liquid extraction. The oil-cyclohexane mixture was then washed with water until the decanted washing water reached $\mathrm{pH}$. Finally, the oil-cyclohexane mixture was distilled in a rotary evaporator at $60{ }^{\circ} \mathrm{C}$ under vacuum (Heidolph ${ }^{\mathrm{TM}}$ HEI-VAP ADVANTAGE model rotary evaporator and VACUUBRAND ${ }^{\mathrm{TM}}$ VARIO $^{\mathrm{TM}}$ PC3004 vacuum system). The free fatty acid content of the hydrolysed walnut oil was $18.0 \%$ OA eq. Next, walnut oils having a free fatty acid content of $3.1,7.6$ and $11.7 \%$ OA eq. were prepared by mixing ( $49.0 \mathrm{wt} . \%$ refined oil $+51.0 \mathrm{wt} . \%$ crude oil), $(59.0 \mathrm{wt} . \%$ refined oil $+41.0 \mathrm{wt} \%$ crude oil hydrolysed) and (35.6wt.\% refined oil +64.4 wt.\% crude oil hydrolysed), respectively.

Liquid-liquid extraction method: Preliminary experiments (not presented) investigated the parameters for the extraction and decantation steps that would maintain mass transfer equilibrium. The liquid-liquid extraction was carried out in a separatory funnel by mixing walnut oil (30-50 g oil) with solvent in different oil/solvent ratios. Each component (oil and solvent) was weighed on a scaled analytical balance (METTLER, Switzerland) accurate to $\pm 0.005 \mathrm{~g}$. Mixtures were then shaken vigorously for $30 \mathrm{~min}$ in a mechanical device (Rotachoc, Chopin Technologies, France) at $27^{\circ} \mathrm{C}$ and in a planetary movement at $60 \mathrm{rpm}$. The mixtures were then allowed to rest for $18 \mathrm{~h}$ at $7^{\circ} \mathrm{C}$ in a cold room. The demixing process assisted by subsequent cooling helped reduce the loss of oil as demonstrated in Citeau et al. (2018). After demixing, the two phases became clear with a well-defined interface. The two phases, the alcohol-rich phase supernatant (AP), and the oil-rich phase decanted fluid(OP) were then separated and analysed. To avoid mixing, the alcohol-rich phase was removed using a Pasteur pipette, after which the oil-rich phase was drained from the separatory funnel.

A design of experiments was implemented to study the effect of the initial FFA content in oil, the oil/solvent ratio $(\mathrm{O} /$ $\mathrm{S})$, the ethanol content in solvent and their interactions, on the oil quality and on the extraction efficiency. Considering the number of factors (3) and their levels (3) (Tab. 1), a BoxBehnken design was chosen (Bezerra et al., 2008). The FFA content interval was chosen with values exceeding $2 \% \mathrm{OA}$ eq.; starting at this value, acidity becomes very problematic for the conventional refining methods: chemical method cannot be performed without high losses of neutral oil, and physical refining damages oil (Bhosle and Subramanian, 2005; Rodrigues et al., 2014). An ethanol-water azeotrope was chosen as maximum because a maximal ethanol content in solvent requires specific and costly distillation equipment in industry and would be less economical. The minimum ethanol content was not too low because of the reduction of the extraction efficiency with the presence of water in solvent. An ethanol content in solvent of $88-96 \%$ was recommended in previous works (Batista et al., 1999; Gonçalves et al., 2002; Cuevas et al., 2009; Rodrigues et al., 2014). Oil/solvent ratios were in the same interval as those tested in Gonçalves et al. (2016). Interval values were expanded to obtain a significant difference in the results of the deacidification tests.

Statistical analysis and model: The GLM procedure from SAS software (SAS Institute, North Carolina) was used to process data, to analyse the regression and to model the response surface. This procedure uses the least squares method 
for determining the correlation between multivariable linear models. The response surface methodology modelled the effects of the various factors and their interactions on the response as a second order polynomial (Eq. (1)). The studied responses were the FFA extraction yield and the neutral oil losses. Statistically non-significant factors $(p<0.05)$ were gradually deleted from the full model according to the backward selection method in order to improve the fit of the equation to the experimental data and simplify the model (Confais and Le Guen, 2006).

$$
y=a_{0}+\sum a_{i} x_{i}+\sum a_{i i} x_{i}^{2}+\sum a_{i j} x_{i} x_{j}+\triangle+e .
$$

In (1), $y$ is the response: FFA extraction yield and neutral oil losses, $a_{0}$ is the constant coefficient, $a_{i}$ and $a_{j}$ are respectively the coefficients of factors $i$ and $j, x_{i}$ and $x_{j}$ are the coded levels of the factors $i$ and $j, \Delta$ is the lack of adjustment and $e$ is the experimental error.

\subsection{Multistage crossflow extraction}

Material: The experiment was carried out on crude walnut oil at 5.8\% OA eq. (the same as used in the first experiment) and using aqueous ethanol at 70.0, 82.8, 88.6, and 95.6 wt.\% alcohol prepared from demineralised water and anhydrous ethanol (both HPLC grade, Fisher). The composition of the walnut oil was 5.8\% FFA, 4.7\% DAG and 90.4\% TAG (measured according to an adapted IUPAC 6.002).

Butyl benzyl phthalate 98\% (BBP; supplied by SigmaAldrich) was added to crude oil. The initial concentration of BBP measured by gas chromatography-mass spectrometry GC-MS method, was $116.5 \pm 0.5 \mathrm{ppm}$.

Method: The method of liquid-liquid extraction was similar to the one used in the first experiment but the extraction stages were repeated 3-4 times to minimise the FFA residual content. Extractions were performed by a succession of oil-solvent mixing and demixing stages, similar to a multistage crossflow extraction. More precisely, $100 \mathrm{~g}$ of oil was first mixed at $27^{\circ} \mathrm{C}$ with $200 \mathrm{~g}$ of aqueous ethanol in a separatory funnel (mechanical stirring for $30 \mathrm{~min}$ in the Rotachoc). Then, the mixture was stored for $18 \mathrm{~h}$ at $7^{\circ} \mathrm{C}$ in a cold room. After demixing, the two phases (alcohol-rich phase and oil-rich phase), were separated. The solvent content of both phases and the oil acidity of the distilled oil-phase sample were then determined. The oilrich phase was then poured into a clean separatory funnel and mixed with fresh ethanol under the same operating conditions as in the first mixing step. The aqueous ethanol was added in an amount depending on the volatile content in the oil-rich phase in order to maintain a $\mathrm{S} / \mathrm{O}$ ratio of around $2.0 \mathrm{~g} / \mathrm{g}$ (corresponding to an $\mathrm{O} / \mathrm{S}$ ratio of $0.5 \mathrm{~g} / \mathrm{g}$ ) at each mixing stage. The mixing-demixing stages were repeated $3-$ 4 times. To avoid contamination by phthalates during extraction, separation, and sampling, only glassware (separating funnel, beaker, glass pipettes) was used, rinsed three times using HPLC grade hexane, then dried in the oven. The experiments with 88.6 and $95.6 \mathrm{wt} \%$ alcohol were repeated twice. Average values and standard deviations (as error bars) are presented in Figure 3.

\subsection{Analytical methods and calculations}

Determination of solvent content: The solvent content of each phase i.e. the solvent-rich phase and oil-rich phase (W3, wt.\%) was determined by mass loss of the sample in a vacuum oven (Memmert, Switzerland) at $103{ }^{\circ} \mathrm{C}$ for $13 \mathrm{~h}$ :

$$
W_{3}=100 . \frac{m_{s p l}-m_{D M}}{m_{s p l}},
$$

where $m_{s p l}$ is the mass of the sample (oil or alcohol-rich phase) before evaporation $(\mathrm{g})$ and $m_{D M}$ is the mass of the sample after desiccation $(\mathrm{g})$.

Determination of FFA content in initial and treated oil: The free fatty acid content was determined for crude and distilled oil by titration with a standardised alkali solution (KOH) according to ISO 660: 2009. The free fatty acid content in oil $\left(W_{F F A}^{\text {oil }}\right)$ was expressed in $\mathrm{g}$ oleic acid equivalent $/ 100 \mathrm{~g}$ oil:

$$
\boldsymbol{W}_{\mathrm{FFA}}^{\mathrm{oil}}=\frac{\boldsymbol{V}_{\mathrm{KOH}} \times \boldsymbol{C}_{\mathrm{KOH}} \times 282}{\boldsymbol{m}_{\mathrm{oil}}} \times 100,
$$

where $V_{K O H}$ is the titration volume (L), $C_{K O H}$ is the normality of $\mathrm{KOH}$ solution $(\mathrm{mol} / \mathrm{L}), \mathrm{m}_{\mathrm{oil}}$ is the mass of the oil sample $(\mathrm{g})$, and 282 is the molar mass of oleic acid $(\mathrm{g} / \mathrm{mol})$.

Acylglycerol composition: The glyceride composition was measured according to adapted IUPAC 6.002.

Phase composition: The compositions of the separated phases were calculated according to the following equations:

$$
\begin{gathered}
W_{2}=\frac{W_{F F A}^{\text {oilp }}}{100} *\left(100-W_{3}\right), \\
W_{1}=100-W_{2}-W_{3},
\end{gathered}
$$

where $W_{3}$ is the solvent content determined by equation (2) (wt.\%), $W_{F F A}^{\text {oilp }}$ is the FFA content in distilled oil of the phase $p$ (oil-rich phase or alcohol-rich phase) (\% OA eq.), $W_{2}$ and $W_{1}$ are respectively the FFA content and the neutral oil content in the phases (by wt.\%).

Free Fatty Acid extraction yields and neutral oil losses: The extraction yield of free fatty acids or losses of neutral oil in alcoholic phases were determined according to equation (6):

$$
\begin{aligned}
\boldsymbol{t}_{\boldsymbol{i}} & =100 \cdot \frac{\left(\boldsymbol{m}_{\boldsymbol{i}}^{\mathrm{IM}}-\boldsymbol{m}_{\boldsymbol{i}}^{\mathrm{OP}}\right)}{\boldsymbol{m}_{\boldsymbol{i}}^{\mathrm{IM}}} \\
& =100 \cdot \frac{\left(\boldsymbol{m}^{\mathrm{IM}} \times \boldsymbol{W}_{i}^{\mathrm{IM}}\right)-\left(\boldsymbol{m}^{\mathrm{OP}} \times \boldsymbol{W}_{i}^{\mathrm{OP}}\right)}{\boldsymbol{m}^{\mathrm{IM}} \times \boldsymbol{W}_{i}^{\mathrm{IM}}},
\end{aligned}
$$

where $t_{i}$ is the extraction yield or loss of the component $i$ (FFA or neutral oil) $(\%), m_{i}^{I M}$ and $m_{i}^{O P}$ are the masses of the component $i$ in the initial mixture and in the oil-rich phase, respectively $(\mathrm{g}), W_{i}^{I M}$ and $W_{i}^{O P}$ are the content of the component $i$ in the initial mixture and in the oil-rich phase (\%), and $m_{I M}$ and $m_{O P}$ are the masses of the initial mixture and the oil-rich phase $(\mathrm{g})$. 
Butyl benzyl phthalate concentration was measured by the gas chromatography-mass spectrometry GC-MS method. Briefly, $1 \mathrm{~g}$ of oil was extracted with acetonitrile and the extract was purified by dispersive SPE prior to GC-MS analysis (using $\mathrm{m} / \mathrm{z}$ 149). The quantification is done with an external calibration after correction by internal deuterated standards. All the analyses were realised in the ITERG laboratory which is accredited under ISO/CEI 17025: 2017 for this determination.

\section{Results and discussion}

\subsection{Combined effects of initial FFA content, ethanol content and O/S ratio}

The operating conditions of the design of experiment, the final oil acidity, and the extraction yields calculated according to equation (6) are summarised in Table 2. It also presents the compositions of the phases before and after demixing, depending on the composition of the initial mixture.

The statistical analysis of the design helped formulate simplified models representing the FFA extraction yield (Eq. (7)) and the neutral oil (NO) losses (Eq. (8)) depending on the $\mathrm{O} / \mathrm{S}$ ratio, the initial free fatty content in oil, and the ethanol content in the solvent. Results of the ANOVA are given in Table A1.

$$
\begin{aligned}
t_{F F A}= & 49.803+11.863 * X_{E t O H}-6.848 * X_{O} / s \\
+ & 3.468 * X_{O A i}, \\
t_{N O} & =1.280+1.337 . X_{E t O H}-0.651 . X_{O} / s \\
& +0.638 .\left(X_{E t O H}\right)^{2}-0.374 . X_{E t O H} \cdot X_{O} / s
\end{aligned}
$$

where $t_{F F A}$ is the FFA extraction yield (wt.\% on initial FFA mass), $t_{N O}$ is the neutral oil loss (wt.\% of initial neutral oil mass) and $X_{O A i}, X_{E t O H}$ and $X_{o}$ are the initial free fatty acid content in oil, the ethanol content in solvent, and the oil/solvent ratio in coded value $(-1 ;+1)$.

FFA extraction yield: According to the statistical analysis $\left(F=\frac{M S_{\text {model }}}{M S_{\text {error }}}=53.9\right.$ with $M S$ : Mean Square; $p<0.0001$ and $\left.R^{2}=0.931\right)$, the variables $\left(X_{O A i}, X_{E t O H}\right.$ and $\left.X_{o} / s\right)$ in the model represented by equation (7) help predict the FFA extraction yield, and the predicted values show a good correlation with the experimental results. Figure 1 shows the variation of the FFA extraction yield predicted by equation (7) for an initial FFA content in oil of $7.5 \%$. The FFA extraction yield increased with the ethanol content in solvent and with the decrease of the $\mathrm{O} / \mathrm{S}$ ratio (or in other words with the increase in the quantity of the solvent relative to the amount of oil (S/O ratio)). The effect of the ethanol content and of the $\mathrm{S} / \mathrm{O}$ ratio on the FFA extraction yield is in accordance with the results reported by Rodrigues et al. (2006) and Gonçalves et al. (2016). According to the equation, the FFA extraction yield also increased with the initial FFA content in oil. The increase of the initial FFA content in oil shifts the response surface upwards.

Neutral oil losses: According to the statistical analysis $\left(F=54.3 ; p<0.0001\right.$ and $\left.R^{2}=0.952\right)$, the variables $\left(X_{E t O H}\right.$, $\left.X_{o / s}\right)$ in the model represented by equation (8) help predict the neutral oil losses and the predicted values show a good correlation with the experimental results. Figure 2 shows the variation of the neutral oil losses predicted by equation (8). The neutral oil losses ranged from 0.3 to $4.6 \%$ of the initial neutral oil mass in those experimental conditions but without achieving a complete deacidification (Tab. 2). Losses increased according to the ethanol content in solvent and with the quantity of the solvent. It is worth noting that these losses did not vary linearly with the ethanol content and were in particular greatly increased beyond 88-90wt.\% EtOH in solvent. Furthermore, as observed by Gonçalves et al. (2016), the increase of the $\mathrm{S} / \mathrm{O}$ ratio had a more significant effect on the neutral oil losses when solvents with higher ethanol contents were used.

\subsection{Multistage crosscurrent extraction}

\subsubsection{Deacidification efficiency}

The operating conditions tested in the experimental design did not sufficiently reduce the final FFA content in oil (the accepted level of free fatty acid content in edible oil is $0.3 \%$ or less according to the Codex Alimentarius, 2009). The influence of the solvent quantity and its water content was then studied in a multistage crossflow extraction. Table 3 summarises the operating conditions, the post-process FFA content of the oil, and the compositions of the phases before and after demixing.

Figures $3 \mathrm{a}$ and $3 \mathrm{~b}$ show the evolution of the global FFA extraction yield and global neutral oil losses depending on the solvent type and on the quantity of solvent used (the cumulated $\mathrm{S} / \mathrm{O}$ ratio depends on the number of mixing stages, Tab. 3). In Figure $3 \mathrm{a}$, as previously presented in Figure 1, the more water the ethanol contains, the lower is the efficiency of FFA extraction, because the FFA solubility in a water-ethanol mixture decreases with the increasing of water content (Gonçalves et al., 2002, 2016; Rodrigues et al., 2006), probably as a result of the increasing polarity of the solvent. Therefore, higher amounts of solvent must be used to compensate for this loss of extraction efficiency. For example, the use of 6.0 and $8.0 \mathrm{~g}$ solvent/g oil having an ethanol content of 95.6 and 88.6 wt.\% respectively, reduced the FFA content in walnut oil from $5.8 \%$ (in crude oil) to $0.3-0.4 \%$ OA eq. (Tab. 3). This corresponds to a final FFA extraction yield of 95-96\% (Fig. 3a).

At the same time, Figure $3 \mathrm{~b}$ shows that the neutral oil losses increased with the amount of solvent used and with the ethanol content in solvent. However, these losses were lower for solvent with a higher water content. Thus, for a final FFA content in walnut oil of $0.3-0.4 \%$, and despite the use of higher quantity of solvent, $88.6 \mathrm{wt} . \% \mathrm{EtOH}$ led to a total neutral oil loss of $4.0 \%$ against $10.6 \%$ for $95.6 \mathrm{wt} . \% \mathrm{EtOH}$. In the experimental design, a higher loss of neutral oil in the solvent beyond an ethanol content of $88-90 \mathrm{wt} \%$ (Fig. 2) was observed.

In Figures $3 a$ and $3 b$, the dotted lines represent the results of modelling the global FFA extraction yield and global neutral oil losses based on the equations (7) and (8). To resolve the equations, the $\mathrm{O} / \mathrm{S}$ ratio was fixed at each extraction stage, as shown in Table 3 (i.e. non-cumulated $\mathrm{O} / \mathrm{S}$ ratio), and the value of the initial FFA content in oil was determined from the results of the equations (7) and (8) at the previous washing stage and 


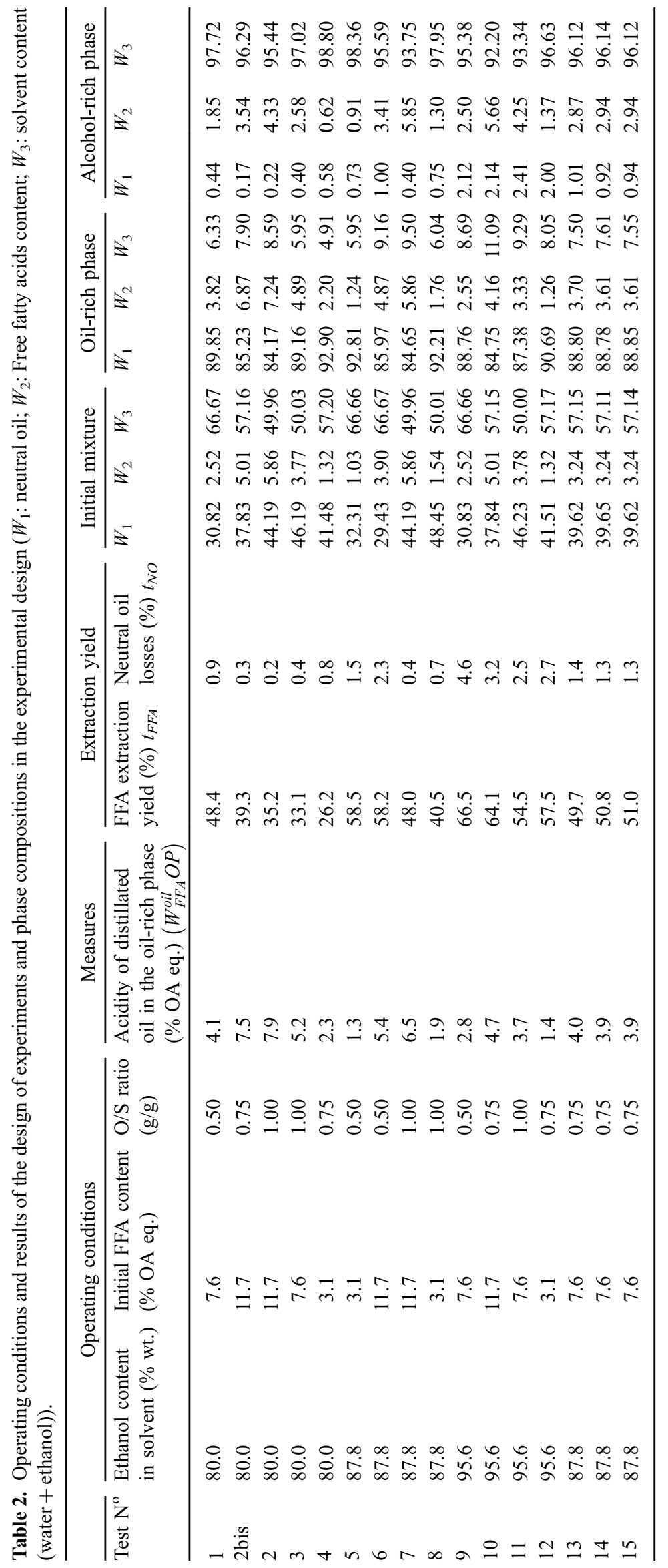


R. Bou Orm et al.: OCL 2020, 27, 35

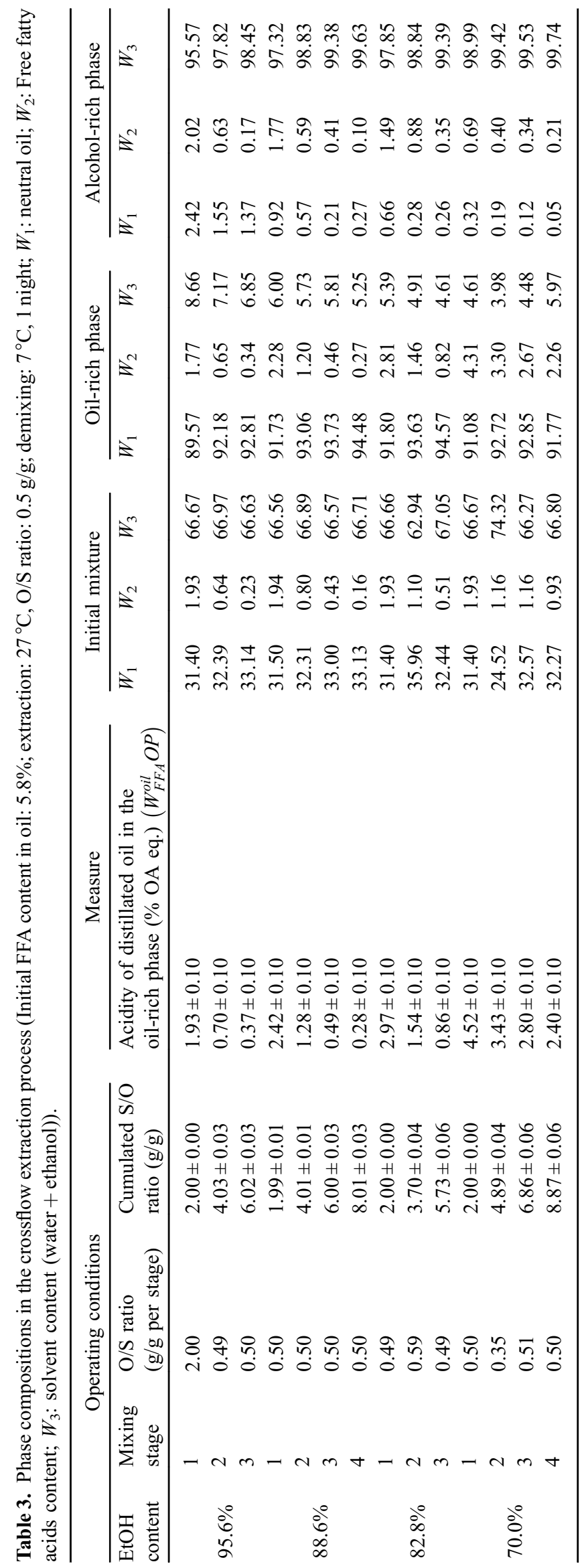

Page 7 of 13 


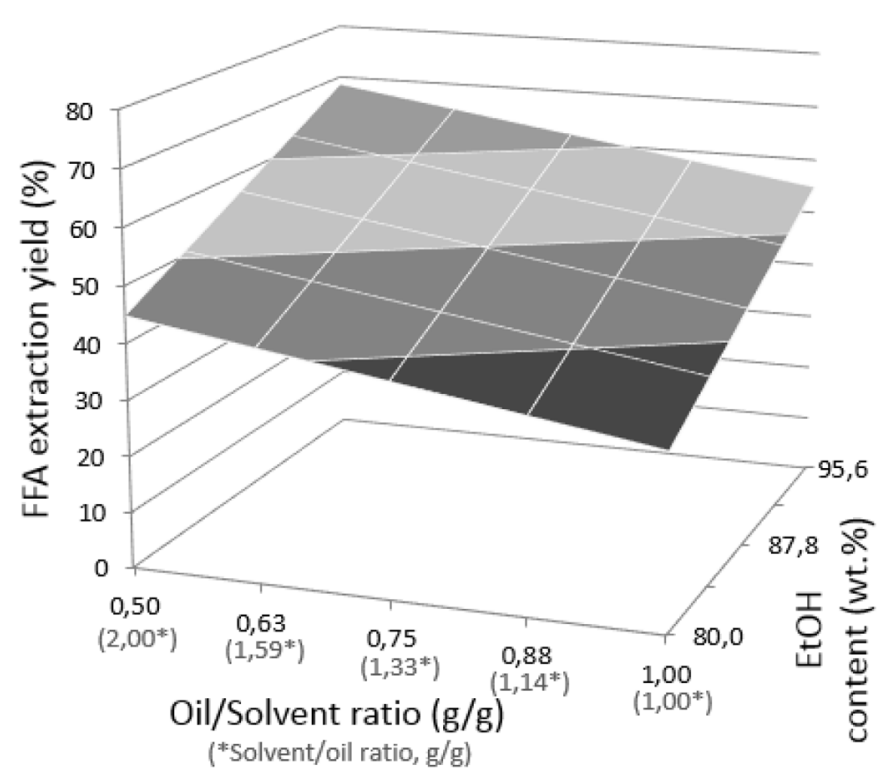

Fig. 1. Response surface of FFA extraction yield predicted by equation (7) for an initial FFA content in oil of $7.5 \% \mathrm{OA}$ eq.

from the mass balances. Global extraction yield or losses were calculated from the mass balances. The model for the FFA extraction yield for solvent at $95.6,88.6$ or $82.8 \mathrm{wt} \% \mathrm{EtOH}$ fitted with the experimental results. However, the model overestimated the FFA extraction yield for $70.0 \mathrm{wt} \%$ EtOH probably, because this ethanol content was not within the range of the operating conditions tested in the experimental design. The model of the global neutral oil losses fitted with the experimental results for 95.6 and $82.8 \mathrm{wt}$ \% EtOH until the 2nd extraction stage, then it overestimated the losses. The high solubility of the neutral oil in the first extraction stages may be explained by the extraction of other polar lipids in crude oil such as phospholipids, monoacylglycerols, diacylglycerols (Shiozawa et al., 2015). Because of their polarity, these components are more miscible than triglycerides in ethanol and would be also removed in the early stages of a crossflow extraction with FFA. Because equation (8) did not take the lipid composition into account, it may overestimate the neutral oil losses from the 2nd stage.

Figure 4 presents the global losses in triacylglycerols ( TAG) and diacylglycerols (DAG) with solvent during the crossflow extractions. As previously observed by Shiozawa et al. (2015), FFA (shown in Fig. 3a) and DAG (shown in Fig. 4) were more easily transferred in ethanolic solvent than TAG. Their greater solubility in ethanol may be explained by the possible hydrogen bonding between the ethanol hydroxyl group and the DAG glycerol molecule or the carboxyl group hydrogen in FFA. Just as with FFA, the extraction efficiency of DAG and TAG decreased with the decrease of the ethanol content in solvent.

\subsubsection{Decontamination efficiency}

Crude oil was contaminated with $116.5 \pm 0.5 \mathrm{ppm}$ butyl benzyl phthalate (BBP). In comparison, the BBP content in the range $22-252 \times 10^{-3} \mathrm{ppm}$ was measured by Bi et al. (2013) in different kinds of edible oils purchased from a U.S. retail market. Di-2-(ethylhexyl) phthalate (DEHP) is the main

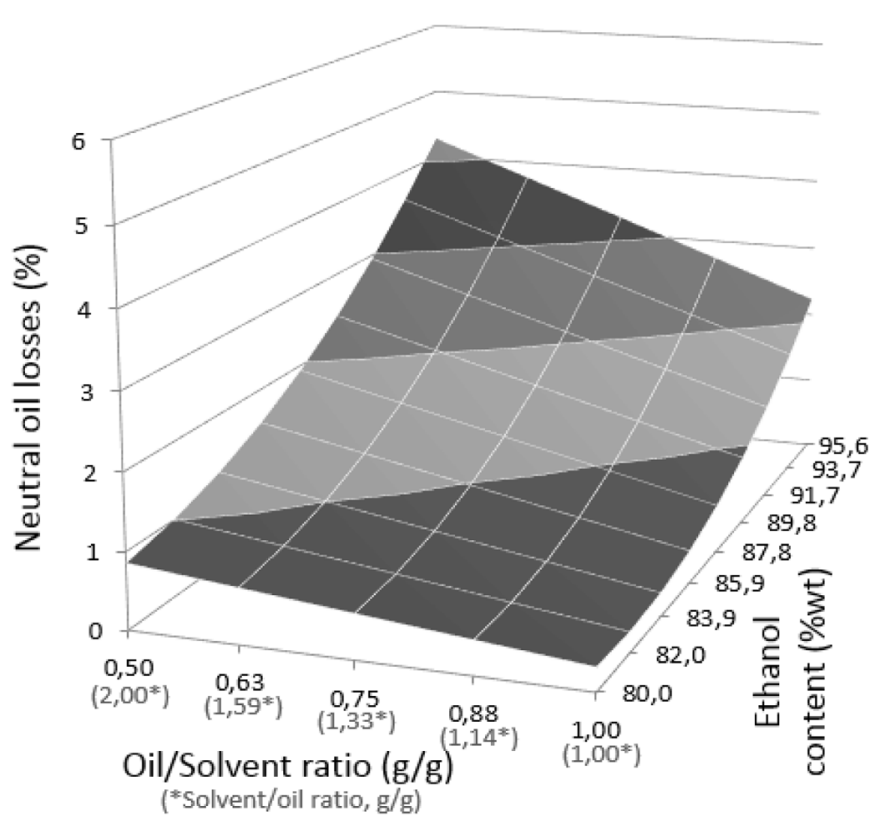

Fig. 2. Response surface of neutral oil losses predicted by equation (8).

phthalate used as plasticizer and it is generally found in higher concentration than BBP in oil (Bi et al., 2013). It should therefore be a relevant marker for the decontamination study. However, to avoid a contamination of oil samples by DEHP traces in cleaned material during our experiments and thus to avoid a bias in the results, BBP rather than DEHP was preferably chosen as a marker. Figure 5a shows the evolution of the cumulative extraction yield of BBP as a function of the ethanol content in solvent. The use of 70.0, 82.8, 95.6 wt.\% $\mathrm{EtOH}$ in three extraction stages of a crossflow removed $73 \%$, $88 \%$ and $94 \%$ of BBP mass from oil, respectively. Thus, the less water ethanol contains, the more efficient the extraction of BBP. According to European commission regulation (ECR No. $10 / 2011$ ), the specific migration limit of BBP in food is $30 \mathrm{ppm}$ (Lacoste, 2014). Extractions with $82.8 \%$ and 95.6 wt.\% EtOH succeeded in reducing the BBP content below this limit from the 2 nd extraction stage while extraction with 70.0 wt.\% EtOH required more solvent (Fig. $5 b$ ).

The distribution coefficient of BBP between the alcoholrich phase and oil-rich phase $\left(k_{B B P} ;-\right)$ was calculated from the content of BBP in the alcohol-rich phase $\left(W_{B B P}^{A P}\right)$ and in the oilrich phase $\left(W_{B B P}^{O P}\right)$, as follows:

$$
k_{B B P}=\frac{W_{B B P}^{A P}}{W_{B B P}^{O P}} .
$$

Figure $5 \mathrm{~b}$ presents the evolution of the BBP distribution coefficient as a function of the BBP content in oil at each extraction stage of the crossflow and for solvents with various ethanol content. As observed, the proportion of BBP solubilised in the alcohol-rich phase compared to that in the oil-rich phase at steady state decreased with the decrease of the BBP content in oil. It can then be concluded that the extraction efficiency decreases when BBP was in trace form. More work will be required to prove and optimise the efficient extraction of BBP traces (and phthalates in general) from oils with different initial quality. 

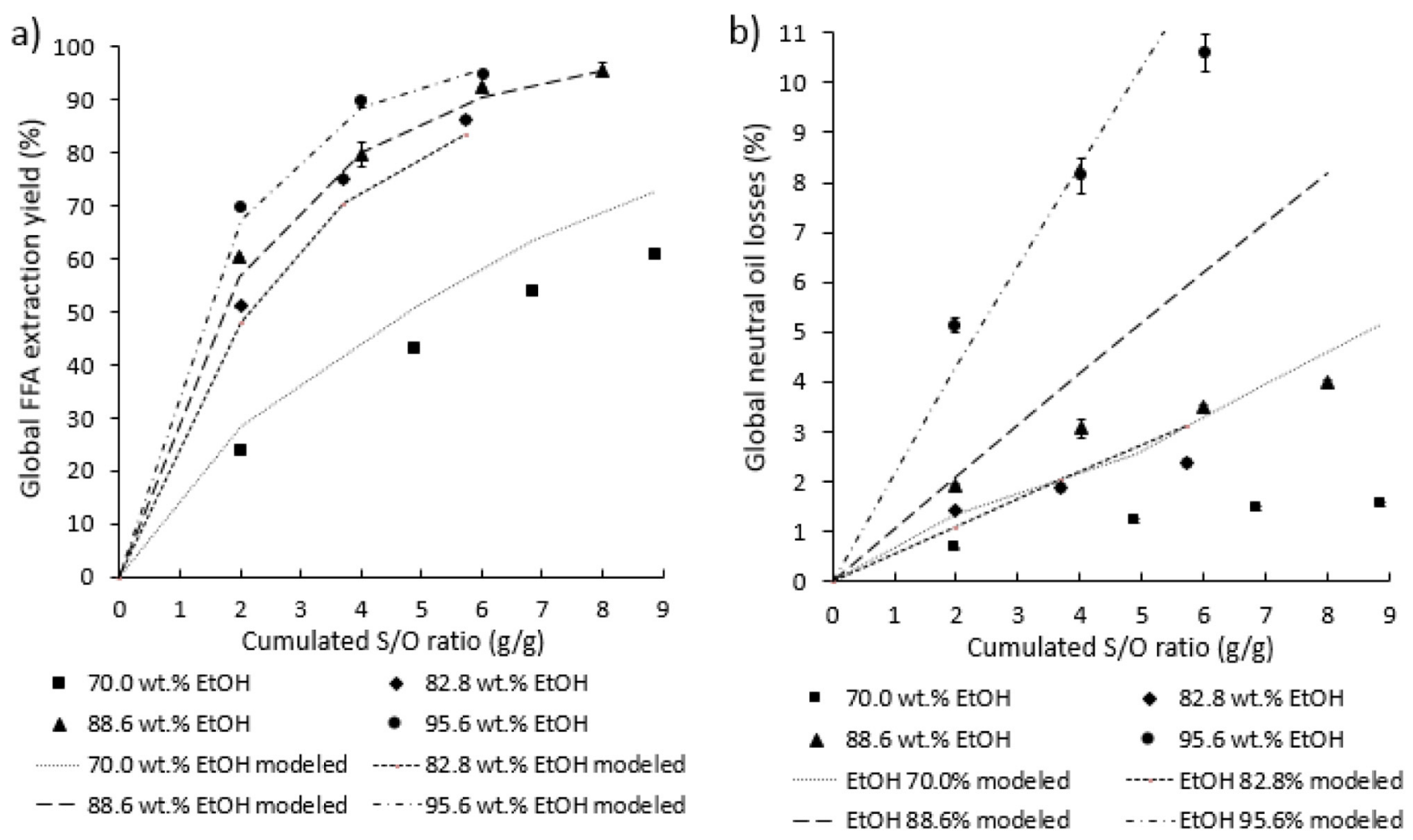

Fig. 3. Influence of the hydroethanolic solvent on (a) the extraction efficiency of FFA and (b) neutral oil losses in a multistage crossflow extraction.

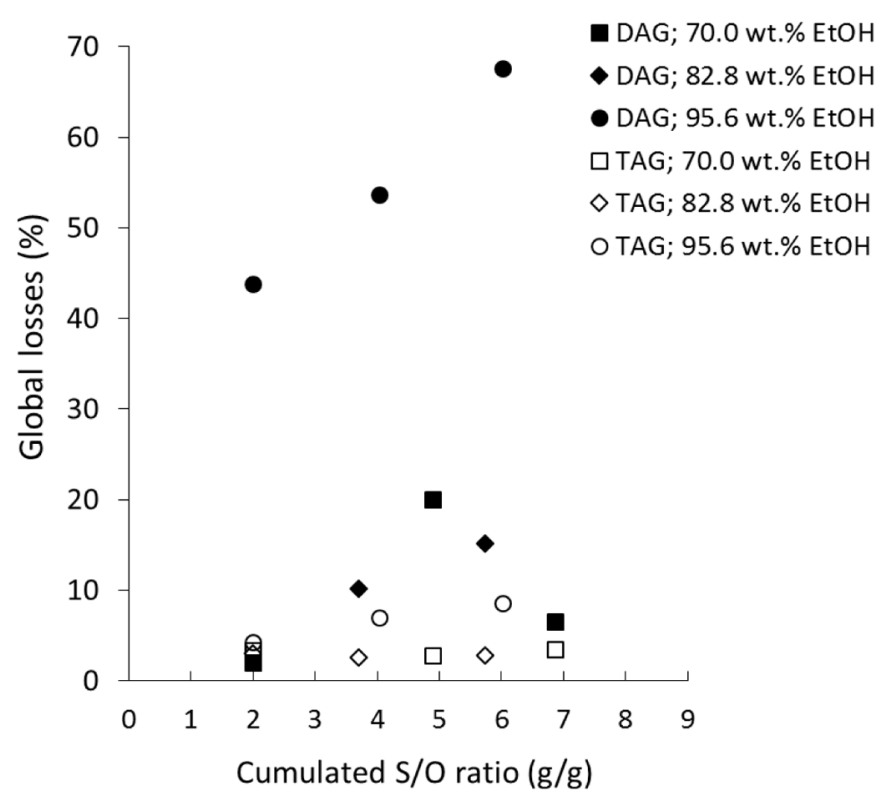

Fig. 4. Extraction yield of triacylglycerols (TAG) and diacylglycerols (DAG) as a function of the ethanol-water content in solvent.

\subsubsection{Economic assessment of the deacidification method}

The optimisation of the deacidification process ultimately depends on a trade-off between the target final oil acidity and the operating costs to reach it. The operating costs include some of the highest costs: the loss of profits due to the loss of matter and the cost of the solvent distillation. In first economic assessment, the energy required for the solvent evaporation was calculated depending on the solvent/oil ratio $\left(R_{s / o}, \mathrm{~kg} / \mathrm{kg}\right)$, the ethanol content in solvent $\left(W_{E t O H}, \mathrm{~kg} / \mathrm{kg}\right)$, and the latent heat of vaporisations of ethanol and water $\left(\Delta H_{E t O H}=0.238 \mathrm{kWh} / \mathrm{kg} ; \Delta H_{H_{2} O}=0.627 \mathrm{kWh} / \mathrm{kg}\right)$, as follows ( $E$ in $\mathrm{kWh} / \mathrm{kg}$ oil):

$$
\begin{aligned}
E & =W_{E t O H} * R_{s / o} * \Delta H_{E t O H}+\left(1-W_{E t O H}\right) * R_{s / o} \\
& * \Delta H_{H 2 O} .
\end{aligned}
$$

The energy required to warm liquid to the boiling temperature (or to cool liquid to the extraction temperature) was neglected in this energy consumption estimate because, in industrial processes, it can be recovered from heat exchangers used to cool (or warm) liquid flows. The price of thermal energy was estimated at $0.058 € \mathrm{kWh}(=40 € / \mathrm{t}$ steam $/ 700 \mathrm{kWh} /$ $\mathrm{t}$ steam production). The loss of profits related to neutral oil losses was estimated at $1 € / \mathrm{kg}$ oil $\left(P_{o i l}=\right.$ price for edible vegetable oil, which is certainly an underestimate for walnut oil). The cost of neutral oil losses $\left(C_{\text {losses }}, € / \mathrm{kg}\right.$ oil $)$ was calculated as:

$$
C_{\text {losses }}=\frac{t_{N O}}{100} *\left(1-\frac{W_{F F A}^{O i l}}{100}\right) * P_{\text {oil }}
$$

Where $t_{N O}$ is the proportion of global neutral oil losses $(\mathrm{g} / 100 \mathrm{~g}$ initial NO), $W_{F F A}^{O i l}$ is the free fatty acids content in initial oil (\% OA eq.), and $P_{o i l}$ is the price of edible oil ( $€ / \mathrm{kg}$ oil).

The operating costs $\left(C_{t o t} ; € / \mathrm{kg}\right.$ crude oil $)$, including neutral oil losses and solvent distillation, was then calculated as: 

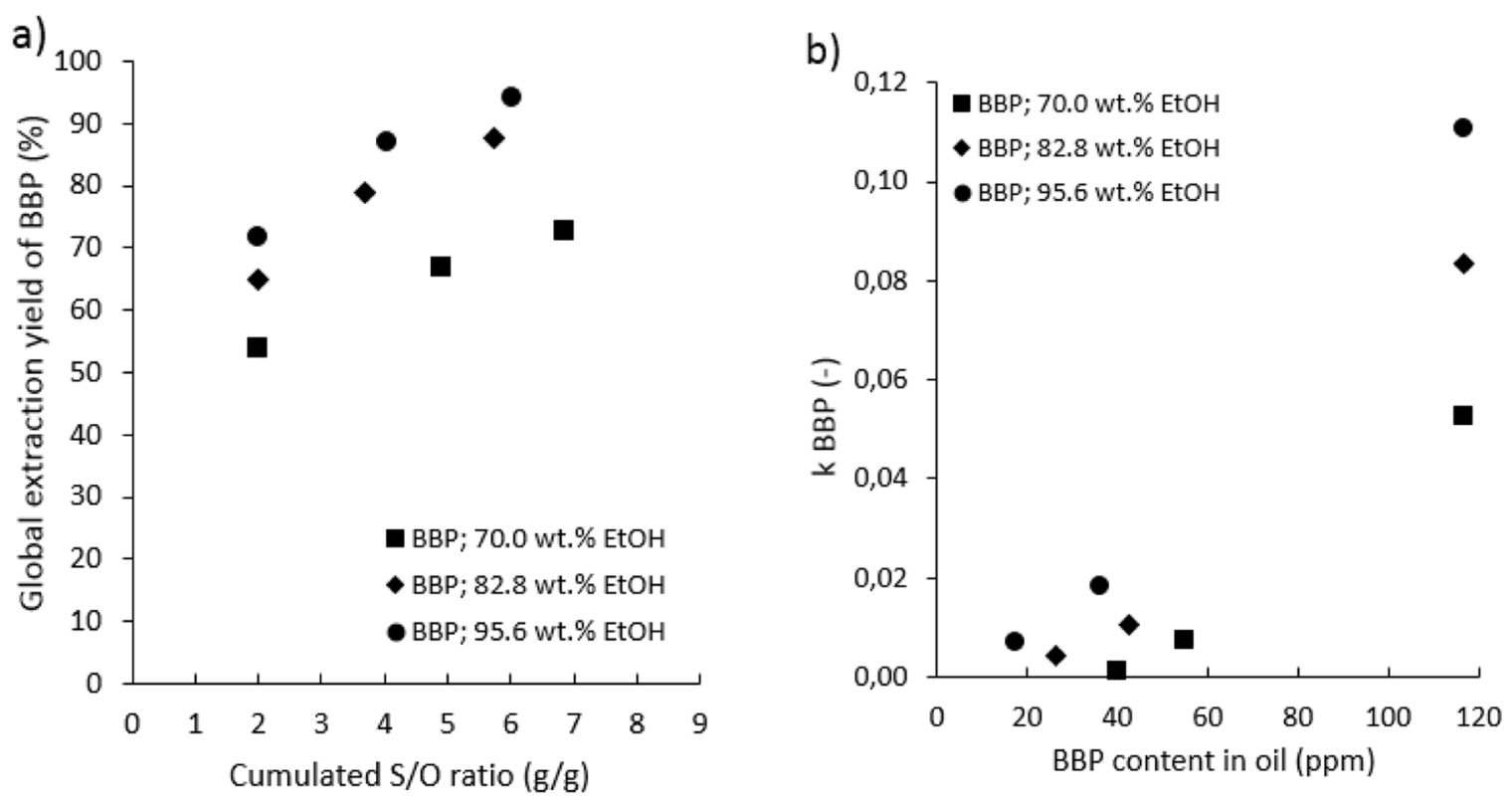

Fig. 5. (a) Extraction yield of butyl benzyl phthalate (BBP) and (b) distribution coefficient of BBP between the alcohol-rich phase and oil-rich phase as a function of the ethanol-water content in solvent.

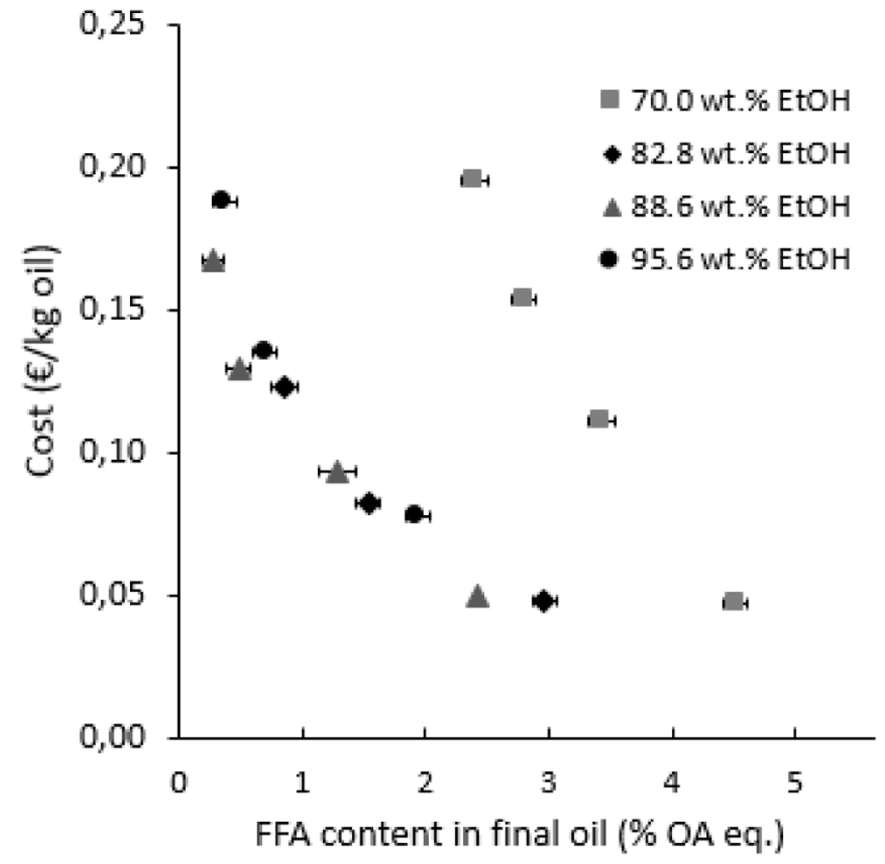

Fig. 6. Operating cost of the liquid-liquid extraction including the cost of neutral oil losses and of the solvent distillation for neutral oil price estimated at $1 € / \mathrm{kg}$ oil.

$$
C_{\text {tot }}=E * 0.058+C_{\text {losses }} .
$$

This parameter, together with the oil acidity reached at each stage (Fig. 6), enables one to simultaneously take into account the quantity of solvent used and the losses in neutral oil in the comparison of the efficiency of solvent with differing ethanol content. Thus, despite the use of a large amount of

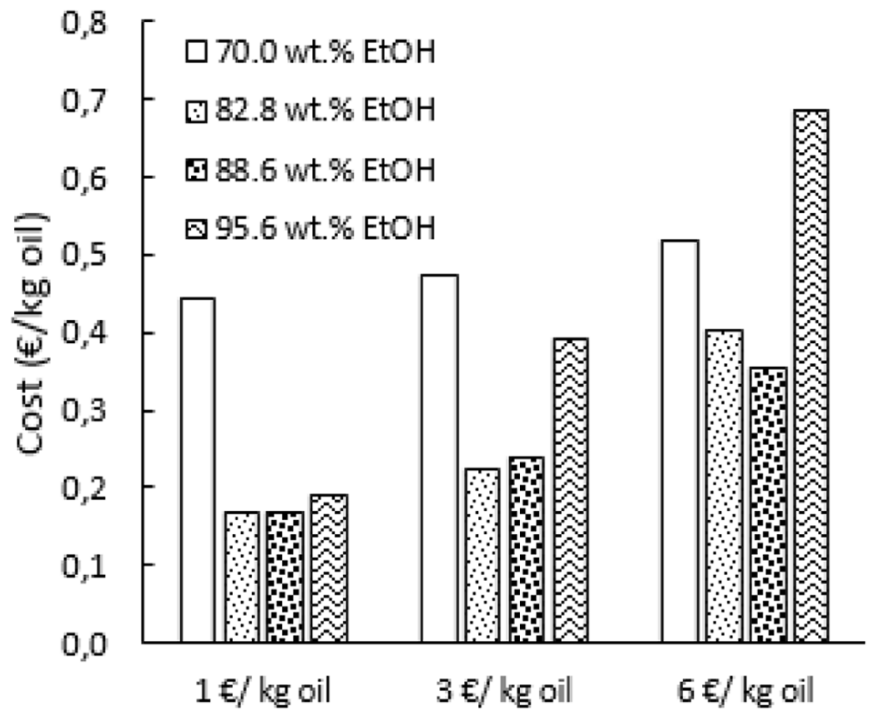

Fig. 7. Influence of the neutral oil price on the operating cost of liquid-liquid extraction according to equation (12), for a reduction in acidity from 5.8 to $0.3 \% \mathrm{AO}$ eq.

solvent to achieve an oil acidity of $0.3 \%$ OA eq. with 88.6 wt. $\%$ $\mathrm{EtOH}$, the operating costs were $71 \%$ of those for extraction using $\mathrm{EtOH}$ at $95.6 \mathrm{wt} . \%$ for a price of edible oil equalling $1 € /$ $\mathrm{kg}$ oil. For high-value oil such as walnut oil, a price of edible oil higher than $1 € / \mathrm{kg}$ would make the use of solvent with higher water content more attractive than $95.6 \mathrm{wt} . \% \mathrm{EtOH}$ as shown in Figure 7. (In Fig. 7, the operating cost of extractions with $\mathrm{EtOH}$ at 70.0 and $82.8 \mathrm{wt} \% \%$ were extrapolated for a final acidity of $0.3 \%$ AO eq., using Eqs. (7) and (8)). Thus, our results suggest that the optimal ethanol content in solvent 
would be around $82-90 \mathrm{wt} . \%$; leading to a lower consumption of solvent compared to more aqueous solvents (such as 70.0 wt.\% EtOH) while minimizing the neutral oil losses (in comparison to $95.6 \mathrm{wt} . \% \mathrm{EtOH})$.

The costs of solvent evaporation were $47 \%$ and $77 \%$ of the operating costs of extractions with $\mathrm{EtOH}$ at 95.6 and $88.6 \mathrm{wt}$. $\%$, respectively, according to equation (12) (and for a neutral oil price of $1 € / \mathrm{kg}$ oil). Note: the cost of evaporating the solvent could be decreased by using a double-effect evaporator with reuse of the latent heat of the solvent vapours to vaporise the residual solvent under reduced pressure.

The cost of solvent regeneration could also be reduced by using membrane filtration. Studies confirmed that membrane filtration has been successfully used to recover organic solvents from oil-solvent mixtures (Kale et al., 1999; Kwiatkowski and Cheryan, 2005; Darvishmanesh et al., 2011; Boam and Lim, 2013; De Melo et al., 2015). This method generates a purified solvent stream (= permeate) and a retentate stream concentrating oil that should still be distilled. The advantages of this method are that its operation is less energy-consuming than distillation and it reduces the amount of solvent to be distilled, thereby reducing the evaporation costs. For example, the study conducted by Kwiatkowski and Cheryan (2005) showed that nanofiltration carried out on corn oil-ethanol miscella in two filtration stages made it possible to recover $97-98 \%$ of solvent feed by concentrating the retentate stream from 2.5 to $96 \mathrm{~g}$ oil/L. This would correspond to a reduction in energy consumption of 97 $98 \%$ compared to the distillation process without filtration.

Recent works showed that phase separation following ethanol contact with oil results in a partial loss of some micronutrients such as tocopherols, carotenoids, $\gamma$-oryzanol or sterols (Rodrigues et al., 2006, 2014; Gonçalves et al., 2007, 2016; Citeau et al., 2018). Studies showed that losses of these lipidic compounds decreases with the increase of water content in the solvent. From the economic point of view, this supports the use of ethanol with the minimal required water content.

\section{Conclusion}

According to the results of the experimental design, FFA extraction yield varied linearly with the ethanol content in solvent, oil/solvent ratio and initial FFA content in oil, while the neutral oil losses followed a more complex relationship with these parameters including an interaction between ethanol content and $\mathrm{O} / \mathrm{S}$ ratio. The decrease of the extraction efficiency of FFA with the decrease of ethanol content in solvent could then be compensated by the use of a higher amount of solvent; the variation of this latter parameter has a significantly lower effect on the neutral oil losses than on FFA extraction yield when the ethanol content in solvent decreased. The study demonstrates that a trade-off between oil losses, deacidification and operating costs can be found. Summarising, the extraction carried out on crude oil containing 5.8\% AO eq. by $88.6 \mathrm{wt} . \% \mathrm{EtOH}$, removed 95-96\% of FFA and $4.0 \%$ of neutral oil mass.

Regarding the extraction of phthalates, ethanol also reduced the BBP content to below $30 \mathrm{ppm}$. However, its extraction efficiency decreased with the decrease of ethanol content in solvent and also when BBP was in trace form.

In order to make this alternative process more economically attractive than the current deacidification processes, supplementary investigations should be carried out on the development of membrane technology for the regeneration of solvent.

Acknowledgment. This work was financially supported by the French Ministry of Agriculture within the CASDAR programme (AAP "recherche technologique" 2016, project DEACOL 2017-2019).

\section{References}

Amaral JS, Casal S, Pereira JA, Seabra RM, Oliveira BPP. 2003. Determination of sterol and fatty acid compositions, oxidative stability, and nutritional value of six walnut (Juglans regia L.) cultivars grown in Portugal. J Agric Food Chem 51: 7698-7702.

Batista E, Monnerat S, Kato K, Stragevitch L, Meirelles AJA. 1999. Liquid-liquid equilibrium for systems of canola oil, oleic acid and short-chain alcohols. J Chem Eng Data 44: 1360-1364.

Bezerra MA, Santelli RE, Oliveira EP, Villar LS, Escaleira LA. 2008. Response surface methodology (RSM) as a tool for optimization in analytical chemistry. Talanta 76(5): 965-977.

Bhosle BM, Subramanian R. 2005. New approaches in deacidification of edible oils - a review. J Food Eng 69(4): 481-494.

Bi X, Pan X, Yuan S, Wang Q. 2013. Plasticizer Contamination in Edible Vegetable Oil in a U.S. Retail Market. J Agric Food Chem 61: 9502-9509.

Boam AT, Lim FW. 2013. Deacidification method. Patent US 8,598,376 B2. Available from http://www.freepatentsonline.com/ 8598376.pdf (Last consult: 2020/02/01).

Chiyoda C, Peixoto ECD, Meirelles AJA, Rodrigues CEC. 2010. Liquid-liquid equilibria for systems composed of refined soybean oil, free fatty acids, ethanol, and water at different temperatures. Fluid Phase Equilib 299(1): 141-147.

Citeau M, Albe Slabi S, Joffre F, Carré P. 2018. Improved rapeseed oil extraction yield and quality via cold separation of ethanol miscella. OCL 25(2).

Codex Alimentarius. 2009. Norme pour les huiles végétales portant un nom spécifique. Codex-Stan 210-1999. Available from http://www. fao.org/3/y2774e/y2774e04.htm (Last consult: 2020/02/01).

Confais J, Le Guen M. 2006. Premiers pas en régression linéaire avec $\mathrm{SAS}^{\circledR}$. Revue MODULAD 35.

Cuevas M, Rodrigues ECC, Meirelles AJA. 2009. Effect of solvent hydration and temperature in the deacidification process of sunflower oil using ethanol. J Food Eng 95(2): 291-297.

Darvishmanesh S, Robberecht T, Luis P, Degrève J, Van der Bruggen B. 2011. Performance of nanofiltration membranes for solvent purification in the oil industry. J Am Oil Chem Soc 88: 1255-1261.

De Melo JRM, Tres MV, Steffens J, Oliveira JV, Di Luccio M. 2015. Desolventizing organic solvent-soybean oil miscella using ultrafiltration ceramic membranes. J Membr Sci 475: 357-366.

European Commission Regulation [ECR]. 2008. Regulation $\mathrm{N}^{\mathrm{o}} 889$ / 2008 of 5 September 2008 laying down detailed rules for the implementation of Council Regulation (EC) $\mathrm{N}^{\mathrm{o}} 834 / 2007$ on organic production and labelling of organic products with regard to organic production, labelling and control. Off J Eur L 250: 1-115.

European Commission Regulation [ECR]. 2011. Regulation No. 10/ 2011 of 14 January 2011 on plastic materials and articles intended to come into contact with food. Off J Eur Union L 12: 1-89.

European Chemical Agency [ECHA]. 2014. Support document to the opinion of the member state committee for identification of benzyl butyl phthalate (BBP) as a substance of very high concern because of its endocrine disrupting properties which cause probable serious effects to human health and the environment which give rise to an equivalent level of concern to those of CMR 
and $\mathrm{PBT} / \mathrm{vPvB}$ substances. Available from https://echa.europa. eu/documents/10162/c5e7a581-db15-4e09-8be9-37d42c5409d8 (Last consult: 2019/11/20).

Frega N, Mozzon M, Lercker G. 1999. Effects of free fatty acids on oxidative stability of vegetable oil. J Am Oil Chem Soc 76(3): 325-329.

Gao P, Liu R, Jin Q, Wang X. 2019. Comparative study of chemical compositions and antioxidant capacities of oils obtained from two species of walnut: Juglans regia and Juglans sigillata. Food Chem 279: 279-287.

Gonçalves CB, Batista E, Meirelles AJA. 2002. Liquid-liquid equilibrium data for the system corn oil + oleic acid + ethanol + water at 298.15 K. J Chem Eng Data 47(3): 416-420.

Gonçalves CB, Pessôa Filho PA, Meirelles AJA. 2007. Partition of nutraceutical compounds in deacidification of palm oil by solvent extraction. J Food Eng 81(1): 21-26.

Gonçalves CB, Rodrigues CEC, Marcon EC, Meirelles AJA. 2016. Deacidification of palm oil by solvent extraction. Sep Purif Technol 160(29): 106-111.

ISO 660: 2009. 2009. Animal and vegetable fats and oils-Determination of acid value and acidity.

ISO/CEI 17025. 2017. General requirements for the competence of testing and calibration laboratories.

IUPAC 6.002. 1992. Determination of mono- and diglycerides by capillary gas chromatography. Section 6: Emulsifiers in standard methods for the analysis of oils, fats and derivatives. Int Union Pure Appl Chem, Published by Blackwell Scientific Publications.

Kale V, Katikaneni SPR, Cheryan M. 1999. Deacidifying rice bran oil by solvent extraction and membrane technology. J Am Oil Chem Soc 76(6): 723-727.

Kwiatkowski JR, Cheryan M. 2005. Recovery of corn oil from ethanol extracts of ground corn using membrane technology. $\mathrm{J} \mathrm{Am}$ Oil Chem Soc 82(3): 221-227.

Lacoste F. 2014. Undesirable substances in vegetable oils: anything to declare? OCL 21(1): A103.

Lacoste F, Joffre F, Coustille JL, Morin O, Soulet B, Brenne E, Griffon H. 2010. Détection de contaminants dans les huiles végétales : bilan à fin 2009. OCL 17(2).

Lowell Center for Sustainable Production [LCSP]. 2011. Phthalates and their alternatives: Health and environmental concerns. Report of University of Massachusetts Lowell. Available from https://ec.europa.eu/environment/aarhus/pdf/35/Annex_11_ report_from_Lowell_Center.pdf (Last consult: 2019/11/20).

Mistry BS, Min DB. 1987. Effects of fatty acids on the oxidative stability of soybean oil. J Food Sci 52: 831-2.
Miyashita K, Takagi T, 1986. Study on the oxidative rate and prooxidant activity of free fatty acids. J Am Oil Chem Soc 63:1380 1384.

Nanni N, Fiselier K, Grob K, Di Pasquale M, Fabrizi L, Aureli P, Coni E. 2011. Contamination of vegetable oils marketed in Italy by phthalic acid esters. Food Control 22:209-14.

Ortiz CM, Vicente AR, Fields RP, Grillo F, Crisosto CH. 2019. Walnut (Juglans regia L.) kernel postharvest deterioration as affected by pellicle integrity, cultivar and oxygen concentration. Postharvest Biol Technol 156: 110948.

Pages X, Morin O, Birot C, Gaud M, Fazeuilh S, Gouband M. 2010. Raffinage des huiles et des corps gras et élimination des contaminants. OCL 17: 86-99

Pina CG, Meirelles AJA. 2000. Deacidification of corn oil by solvent extraction in a perforated rotating disc column. $\mathrm{J} \mathrm{Am} \mathrm{Oil} \mathrm{Chem}$ Soc 77: 553-559.

Poggetti L, Ferfuia C, Chiabà C, Testolin R, Baldini M. 2018. Kernel oil content and oil composition in walnut (Juglans regia L.) accessions from north-eastern Italy. J Sci Food Agric 98: 955-962.

Prasad RBN. 2003. Walnuts and pecans. In: Encyclopedia of Food Sciences and Nutrition.

Rodrigues CEC, Antoniassi R, Meirelles AJA. 2003. Equilibrium data for the system rice bran oil + fatty acids + ethanol + water at 298.2 K. J Chem Eng Data 48: 367-373.

Rodrigues CEC, Silva FA, Marsaioli JrA, Meirelles AJA. 2005. Deacidification of Brazil nut and macadamia nut oils by solvent extraction liquid-liquid equilibrium data at 298.2 K. J Chem Eng Data 50: 517-23.

Rodrigues CEC, Onoyama MM, Meirelles AJA. 2006. Optimization of the rice bran oil deacidification process by liquid-liquid extraction. J Food Eng 73(4): 370-378.

Rodrigues CEC, Gonçalves C, Batista EAC, Meirelles A. 2007. Deacidification of vegetable oils by solvent extraction. Rec Patents Eng 1(1):95-102.

Rodrigues CEC, Gonçalves CB, Marcon EC, Batista EAC, Meirelles AJA. 2014. Deacidification of rice bran oil by liquid-liquid extraction using a renewable solvent. Sep PurifTechnol 132: 84-92.

Shah KJ, Venkatesan TK. 1989. Aqueous isopropyl alcohol for extraction of free fatty acids from oils. $\mathrm{J} \mathrm{Am} \mathrm{Oil} \mathrm{Chem} \mathrm{Soc} \mathrm{66:}$ 783-787.

Shiozawa S, Bessa LCBA, Ferreira MC, Meirelles AJA, Batista EAC. 2015. Liquid-Liquid Equilibrium Data for Fatty Systems Containing Monoacylglycerols and Diacylglycerols. J Chem Eng Data 60: 2371-2379. 


\section{Appendix}

Table A1 shows the analysis of variance for the responses:

FFA extraction yield $\left(t_{F F A}\right)$ and neutral oil losses $\left(t_{N O}\right)$.

\begin{tabular}{|c|c|c|c|c|c|c|c|c|c|c|}
\hline & \multicolumn{5}{|c|}{ FFA extraction yield $\left(t_{F F A}\right)$} & \multicolumn{5}{|c|}{ Neutral oil losses $\left(t_{N O}\right)$} \\
\hline Regression & 1815.24 & 605.08 & 3 & 53.86 & $<0.0001$ & 21.38 & 5.35 & 4 & 54.27 & $<0.0001$ \\
\hline Residual & 134.84 & 11.24 & 12 & & & 1.08 & 0.10 & 11 & & \\
\hline Total & 1950.07 & & 15 & & & 22.47 & & 15 & & \\
\hline$R^{2}$ & 0.931 & & & & & 0.952 & & & & \\
\hline Intercept & \multicolumn{2}{|l|}{49.803} & \multicolumn{2}{|c|}{0.845} & $<0.0001$ & \multicolumn{2}{|l|}{1.280} & \multicolumn{2}{|c|}{0.119} & $<0.0001$ \\
\hline$\alpha_{E t O H}$ & \multicolumn{2}{|l|}{11.863} & \multicolumn{2}{|c|}{1.133} & & \multicolumn{2}{|l|}{1.337} & \multicolumn{2}{|c|}{0.107} & $<0.0001$ \\
\hline$\alpha^{o} / s$ & \multicolumn{2}{|l|}{-6.848} & \multicolumn{2}{|c|}{1.133} & $<0.0001$ & \multicolumn{2}{|l|}{-0.651} & \multicolumn{2}{|c|}{0.107} & $<0.0001$ \\
\hline$\alpha_{O A i}$ & \multicolumn{2}{|l|}{3.468} & \multicolumn{2}{|c|}{1.133} & 0.0099 & \multicolumn{2}{|l|}{ / } & \multicolumn{2}{|l|}{ / } & $>0.05$ \\
\hline
\end{tabular}

Analysis of Variance (ANOVA); SS: Sum of Squares; MS: Mean square; DF: Degrees of freedom; $\mathrm{R}^{2}$ : Correlation coefficient, F=(MS model)/ (MS error); $p$ : probability value.

Cite this article as: Bou Orm R, Citeau M, Comitis A, Savoire R, Harscoat-Schiavo C, Subra-Paternault P, Carré P, Leao JD, Joffre F. 2020. Walnut oil deacidification by liquid-liquid extraction with ethanol in a single- and multistage crossflow process. OCL $27: 35$. 